\title{
Intravenous immunoglobulin in HIV-I infected haemophilic patients
}

\author{
N Wagner, R Bialek, H Radinger, H H Brackmann, M Becker
}

\begin{abstract}
In order to evaluate the efficacy of intravenous immunoglobulin (IVIG) in the early stages of HIV infection (patients without AIDS or AIDS related complex) a prospective controlled open trial was conducted in 36 patients (age 6-19 years) with haemophilia. Eighteen patients received $0.3 \mathrm{~g} / \mathrm{kg}$ IVIG at two week intervals; 18 patients served as controls. Major criteria for the evaluation were progression of HIV disease assessed by the modified Brodt/Helm classification, number of infectious events and HIV associated thrombocytopenia, and the $\mathrm{CD4}+\mathrm{T}$ cell count. After 24 months of evaluation seven patients in the IVIG group and five patients in the control group deteriorated according to their staging, with one patient in each group developing AIDS. Thrombocytopenia and infectious events, but no severe bacterial infections, occurred in both groups in similar numbers. The absolute $\mathrm{CD} 4+T$ cell count decreased by $284 / \mu \mathrm{l}$ in the IVIG group and by $143 / \mu \mathrm{l}$ in the control group respectively (mean values). The statistical analysis of these criteria did not reveal any significant difference.
\end{abstract}

In conclusion, IVIG was not effective in the early stages of HIV infection in patients with haemophilia. IVIG did not slow down the progression of HIV disease and did not prevent the development of an immunodeficiency as assessed by the CD4 + $T$ cell count.

\section{(Arch Dis Child 1992;67:1267-71)}

A large proportion of patients with haemophilia acquired HIV-I infection because of the use of commercial clotting factor concentrates that had not been virus inactivated. ${ }^{1}$ As in other risk groups, HIV infection in patients with haemophilia often leads to deterioration of the immune system and results in AIDS with opportunistic infections. ${ }^{23}$ The progression of HIV infection in paediatric patients with haemophilia is evident but runs a slower course when compared with the progression in adult HIV infected patients with haemophilia. ${ }^{45}$ Paediatric AIDS is more often associated with bacterial infections than it is in AIDS in adults. ${ }^{6}$

The efficacy of intravenous immunoglobulin (IVIG) in primary immunodeficiencies like agammaglobulinaemia and common variable immunodeficiency is well established. ${ }^{7}$ The application of IVIG is largely safe with regard to the frequency of anaphylactic and nonanaphylactic reactions, as well as regarding the transmission of infectious agents. ${ }^{8}$ During recent years, the use of IVIG has been extended to diseases in which a possible immunomodulatory effect of IVIG could be of advantage. Examples of this application of IVIG include the management of idiopathic thrombocytopenic purpura, Kawasaki syndrome, and certain forms of rheumatic disorders. ${ }^{9}$

The use of IVIG in paediatric AIDS was first shown to be effective in 1986, resulting in a decreased number of bacterial infections and in an increase of $\mathrm{CD} 4+\mathrm{T}$ cells. ${ }^{10} \mathrm{~A}$ more recent multicentre trial studying IVIG application in symptomatic HIV disease in children showed a significantly increased time free of severe bacterial infections in the treatment arm, but no effect on mortality was observed. ${ }^{11}$ In the latter study patients with haemophilia were not included.

Therapeutic approaches to HIV infection have changed from treating the clinical manifestations of AIDS only to the development of prophylactic regimens with early use of antiretroviral, antibiotic, and antifungal drugs in an attempt to delay the immunological deterioration and to prevent episodes of opportunistic infections. In this controlled prospective open trial, we studied the effects of IVIG in early stages of HIV infection (patients without AIDS or AIDS related complex) in haemophilic children and adolescents during a 24 month period.

\section{Patients and methods}

INCLUSION CRITERIA

Confirmed diagnosis of HIV infection in patients with haemophilia A or B, persistent generalised lymphadenopathy (according to the definition of the Centers for Disease Control, CDC, Atlanta), or a CD4 $+\mathrm{T}$ cell count of $\angle 35 \%$ of lymphocytes were the criteria used for inclusion in the study. No patients already suffering from AIDS or AIDS related complex (CDC criteria) were included.

Thirty six male patients aged 6 to 19 years (mean age 14.8 years) fulfilled these criteria and were enrolled in the study. The patients or their parents gave their informed consent. For the evaluation matched controlled pairs of patients were formed. All pairs were matched by age and stage of HIV infection. One patient from each pair received IVIG and the other patient received observation only. Eleven pairs (22 patients) were randomly assigned to the treatment or the control group; in seven pairs (14 patients) the patients were assigned to one of the arms according to the patient's or his parents request to receive IVIG or to belong to the control

USA.

Accepted 27 May 1992 
group. At the time of entry no patient had previously been treated with IVIG or antiretroviral drugs.

\section{IVIG APPLICATION}

Patients on the treatment arm were given $0.4 \mathrm{~g} /$ $\mathrm{kg}$ IVIG (Venimmun, Behringwerke AG) on four consecutive days followed by $0.3 \mathrm{~g} / \mathrm{kg}$ IVIG at 14 day intervals. On average, the IVIG infusions lasted a mean (SD) of $2 \cdot 9(0 \cdot 6)$ hours. The study was designed for an evaluation period of 24 months. According to the guidelines of the Bundesministerium fuer Frauen, Familie, Jugend und Gesundheit, of the Federal Republic of Germany, adverse effects were directly reported to the study centre and evaluated for the necessity of terminating the IVIG application.

\section{EVALUATION CRITERIA FOR THE EFFICACY OF IVIG}

The major criteria for studying the effects of IVIG were the progression of disease stage according to the Brodt/Helm classification, 12 the incidence of infectious events and HIV associated thrombocytopenia (defined as a platelet count $\left.<100 \times 10^{9} / \mathrm{l}\right)$, and the CD4+ T cell count. In addition to the opportunistic infections fulfilling the AIDS case definition of the CDC, the following were also included as infectious events: fever of unknown origin for more than one week, recurrent diarrhoea of more than three stools per day for more than one week, herpes zoster, oral candidiasis, pneumonia, bronchitis, sinusitis, and otitis media. The Brodt/Helm classification was used because it does not take account of the patient's age. This is in contrast to the CDC classification system, which would have divided our study group into two different classifications (that is patients above and below 13 years of age) and thus would have complicated the comparison between the study arms. As shown in table 1, the Brodt/Helm classification was modified for this study by using the ratio of CD4 $+\mathrm{T}$ cells to lymphocytes (this is not the ratio of CD4+ $\mathrm{T}$ cells to CD8 $+\mathrm{T}$ cells), which has been shown to be a reliable prognostic indicator of immunological deterioration in HIV infection. ${ }^{5} 13$ During the study physical and laboratory examinations of the patients were performed at the entry and at three month intervals thereafter.

LABORATORY TESTS

The following laboratory tests were performed

Table 1 Modified Brodt/Helm classification of HIV infection

\begin{tabular}{|c|c|}
\hline Stage & Definition \\
\hline $\begin{array}{l}\text { la } \\
\text { lb }\end{array}$ & Healthy seronegative subject at risk of HIV infection \\
\hline $2 a$ & $\begin{array}{l}\text { Healthy seropositive subject, no immunoderici } \\
\text { Seropositive patient with lymphadenopathy } \\
\text { syndrome or CD4+ T cells }<25 \% \text { (of } \\
\text { lymphocytes) }\end{array}$ \\
\hline $2 \mathrm{~b}$ & $\begin{array}{l}\text { Seropositive patient with severe immunodeficiency } \\
\text { and a CD } 4+T \text { cell count of }<350 / \mu l \text { or }<20 \% \text { (of } \\
\text { lymphocytes) }\end{array}$ \\
\hline 3 & AIDS (CDC definition) \\
\hline
\end{tabular}

at three month intervals: red cell count, white cell count, measurement of the erythrocyte sedimentation rate (in $\mathrm{mm}$ in the first hour), liver function tests including alanine aminotransferase and glutamyltransferase by conventional commercial tests (Boehringer), and IgG, $\operatorname{IgA}$, and $\operatorname{IgM}$ by nephelometry. Peripheral lymphocyte subpopulations were assessed by flow cytometry using commercial monoclonal antibody reagents (obtained from Ortho Diagnostics or Becton Dickinson). In case of illness additional diagnostic work-up was performed as clinically indicated: chest radiography, ultrasonography of the abdomen, electroencephalography, microbiological studies and cultures of blood, spinal fluid, throat swabs, stool, and urine.

\section{STATISTICS}

The structural similarity of the IVIG group and the control group was verified for the age of the patients and the CD4+ T cell count at entry by Student's $t$ test and for the initial staging according to the Brodt/Helm classification by Bowker test. ${ }^{14}$ The above listed main criteria to investigate the efficacy of IVIG were considered by the Wilcoxon-Mann-Whitney test and Bowker test. After six and 12 months, interim analyses were performed with increasing significance levels. ${ }^{15}$ Herein the significance levels were $0.5 \%$ for the first interim analysis after six months, $1.4 \%$ for the second interim analysis after 12 months, and $4.5 \%$ for the analysis at the end of the study.

\section{ETHICS}

This study was performed according to the permission of the ethics committee of the medical faculty at the University of Bonn.

\section{Results}

IVIG APPLICATION AND ADVERSE EFFECTS

The evaluation period was a mean (SD) of $24 \cdot 0$ $(2 \cdot 3)$ months in the IVIG group and $24 \cdot 4(1 \cdot 7)$ months in the control group. In five patients one to two infusions were missed during the course of the study. In total, 1018 IVIG infusions were given. In 35 of these 1018 infusions adverse effects were reported. These consisted of headache, nausea, vomiting, fever, and urticaria. No anaphylactic reaction occurred. With the exception of one patient, who was treated with antihistamines and corticosteroids for a nonanaphylactic reaction, no therapeutic interventions were necessary. In four cases the single infusion was stopped due to the adverse reaction. There was no case in which the necessity to discontinue the study was found.

Two patients in the IVIG group and three patients in the control group were begun on zidovudine due to an immunological deterioration during the study period. Four of these five patients also received inhaled pentamidine as primary or secondary prophylaxis of Pneumocystis carinii pneumonia. 
developed AIDS ( $P$ carinii pneumonia) after 12 months of the study and died of cardiac failure after 22 months. A 6 year old patient in the control group also developed AIDS (wasting syndrome) and died one month after completion of the study.

According to the modified Brodt/Helm classification (table 1) one patient in the IVIG group improved, 10 patients did not change their staging, and seven patients showed a progression of their disease during the $\mathbf{2 4}$ months evaluation period. In the control group two patients improved, 11 patients remained stable, and five patients deteriorated. There was no statistically significant difference detected between the two groups (Bowker test, $p>0.05$ ). Table 2 summarises these data.

\section{INFECTIOUS EVENTS AND HIV ASSOCIATED THROMBOCYTOPENIA}

As outlined in table 3, most infectious events that occurred were of minor severity with the exception of the one case of $P$ carinii pneumonia. In both groups, 22 infectious events were counted. At least one episode of HIV associated thrombocytopenia developed in five patients in the IVIG group and in three patients in the

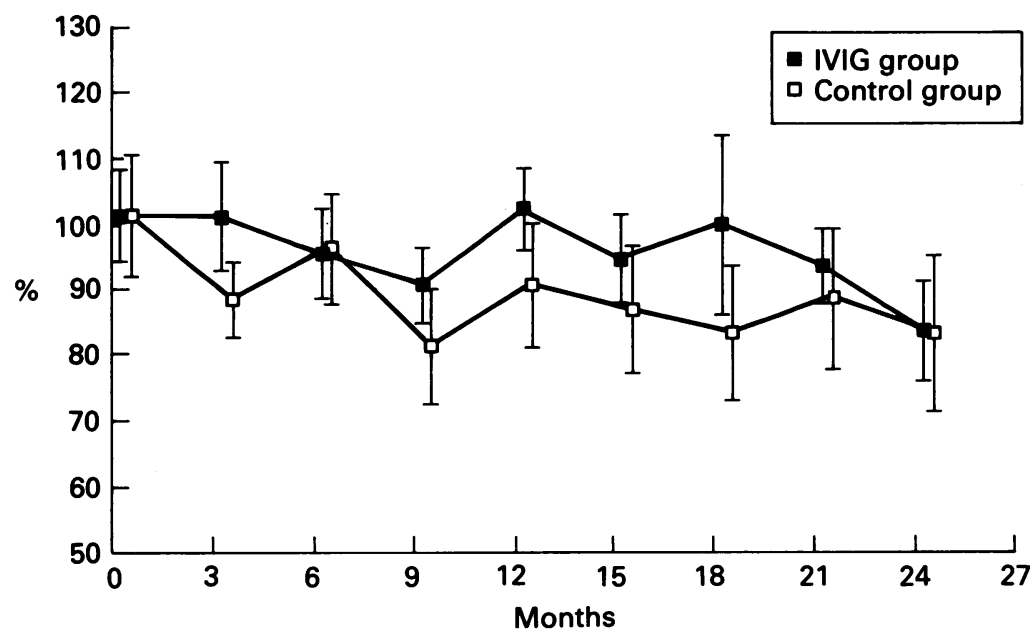

Figure 1 Changes in the ratio of $C D 4+T$ cells to lymphocytes during 24 months represented as mean $(S E)$ percentage of the initial values.

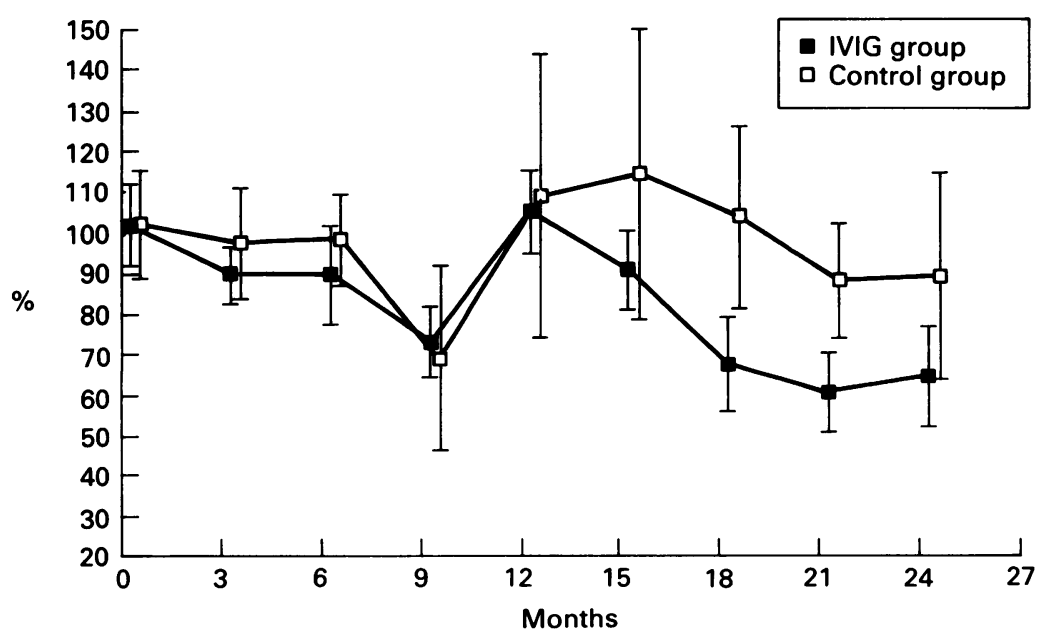

Figure 2 Changes in the absolute CD4+ T cell counts during 24 months represented as mean $(S E)$ percentage of the initial values.
Table 2 Progression in staging in the IVIG group versus the control group assessed by the modified Brodt/Helm classification of HIV infection

\begin{tabular}{lll}
\hline $\begin{array}{l}\text { Staging at entry and } \\
\text { after 24 months }\end{array}$ & $\begin{array}{l}\text { IVIG group } \\
(n=18)\end{array}$ & $\begin{array}{l}\text { Control group } \\
(n=18)\end{array}$ \\
\hline 2b to 2a & 1 & 2 \\
2a to 2a & 7 & 7 \\
2b to 2b & 3 & 4 \\
2a to 2b & 6 & 4 \\
2b to 3 & 1 & 1 \\
\hline
\end{tabular}

Table 3 Infectious events in the IVIG group versus the control group during 24 months evaluation period

\begin{tabular}{lll}
\hline Infectious events & $\begin{array}{l}\text { IVIG group } \\
(n=18)\end{array}$ & $\begin{array}{l}\text { Control group } \\
(n=18)\end{array}$ \\
\hline Otitis media & 6 & 10 \\
Bronchitis, acute & 5 & 4 \\
Infectious diarrhoea & 4 & 1 \\
Oral candidiasis & 1 & 3 \\
Herpes zoster & 1 & 2 \\
Sinusitis & 2 & 1 \\
Pneumonia & 1 & 0 \\
Pcarinii pneumonia & 1 & 0 \\
Fever of unknown origin & 1 &
\end{tabular}

control group. One patient in the IVIG group and two control patients remained thrombocytopenic during the study; the IVIG treated patient experienced recurrent petechiae and epistaxis despite treatment with zidovudine as well. Overall there was no significant difference in the occurrence of infectious events and thrombocytopenia between the two groups (Wilcoxon-Mann-Whitney test, $\mathrm{p}>0.05$ ).

\section{CD4+ T CELL COUNT}

The absolute count of the CD4+ T cells was a mean (SE) of $663(67) / \mu$ l for the IVIG group at the beginning of the study; the corresponding ratio of CD4+ $\mathrm{T}$ cells to lymphocytes was $0 \cdot 241$ $(0.017)$. After 24 months these parameters declined to a mean (SE) of $379(56) / \mu \mathrm{l}$ and to $0.212(0.018)$ respectively. Thus the absolute CD4+ T cell count decreased by a mean (SE) of $284(67) / \mu \mathrm{l}$ and the ratio of CD4+ T cells to lymphocytes decreased by $0.029(0.013)$. In the control group the absolute CD4 $+\mathrm{T}$ cell count was a mean (SE) of $730(98) / \mu l$ initially and declined to $586(76) / \mu$ after 24 months; this represents an average decrease of $144(99) / \mu l$. The ratio of $\mathrm{CD} 4+\mathrm{T}$ cells to lymphocytes decreased by a mean (SE) of $0.038(0.019)$ from $0.246(0.023)$ initially to $0.208(0.023)$ at the last examination. The difference between the mean changes in the two groups was a mean (SE) of $140(119) / \mu l$ referring to the absolute CD4+ T cell count and was $0.009(0.023)$ referring to the ratio of CD4+ $\mathrm{T}$ cells to lymphocytes. In figs 1 and 2 the data of the CD4+ T cell counts (ratio and absolute count) are represented as percentages of the initial values.

The statistical comparison (Wilcoxon-MannWhitney test) did not result in a significant difference for either the absolute CD4 $+\mathrm{T}$ cell count $(p=0.275)$ or for the ratio of CD4+ T cells to lymphocytes $(p=0 \cdot 799)$.

IgG

In the IVIG group mean (SE) IgG concentrations 
in sera were $23 \cdot 14(1.65) \mathrm{g} / \mathrm{l}$ at the beginning and $23 \cdot 16(2 \cdot 09) \mathrm{g} / \mathrm{l}$ after 24 months respectively. IgG concentration in sera of the control group were $22 \cdot 16(2 \cdot 84) \mathrm{g} / \mathrm{l}$ at the entry and 21.38 $(2 \cdot 26) \mathrm{g} / \mathrm{l}$ at the last examination.

\section{Discussion}

To our knowledge this is the first prospective controlled study dealing with the efficacy of IVIG application in the early stages of HIV infection in haemophilic patients. The adverse reactions reported here that accompanied the administration of IVIG were of nonanaphylactic character, and did not lead to discontinuance of the study in any patient. Usually these side effects could be avoided by slowing down the infusion rate. These adverse reactions have been previously well described elsewhere. ${ }^{16} 17$ This study was performed in haemophilic patients classified as having early stages of HIV infection. Patients already suffering from AIDS or AIDS related complex were excluded from the study in order to detect specifically whether there is a measurable therapeutic benefit with early use of this interventional regimen. As shown in table 2 there was a considerable progression of HIV disease in both groups during the 24 months. In the IVIG group seven of 18 patients (38\%) worsened according to the Brodt/Helm classification compared with five of 18 patients $(28 \%)$ in the control group. In each group one patient developed AIDS. The patient in the IVIG group died during the study, the patient in the control group died four weeks after completion of the study. In conclusion, any benefit of the IVIG treatment in delaying disease progression as assessed by the staging of the patients was not detectable. At the beginning of the study no patient received antiretroviral drugs or antibiotics. Due to immunological deterioration, and the in between established efficacy of zidovudine as an antiretroviral agent and of pentamidine for prophylaxis against $P$ carinii pneumonia, these regimens were initiated in five patients. As these patients were rather equally distributed between the two groups, this should not lead to a major bias. We can not rule out, however, that the institution of these drugs outweighs a potential benefit of IVIG.

To date, there has been no published study dealing with IVIG application in HIV infection in haemophiliacs. Therefore the results must be compared with studies of IVIG treatment in other risk groups. The National Institutes of Health multicentre trial in children with vertically transmitted symptomatic HIV infection did not result in a lower mortality in the IVIG group. ${ }^{11}$ Other reports, however, showed appreciable improvement of neurological symptoms such as psychomotor development and other clinical symptoms, such as lymphoid interstitial hyperplasia not directly related to bacterial infections; unfortunately, these studies lacked a control group. ${ }^{18} 19$

Bacterial infections are a major cause of illness in paediatric AIDS or AIDS related complex. ${ }^{62}{ }^{21}$ In this study only mild infections occurred in both groups during the 24 months, with the exception of the one case of $P$ carinii pneumonia. This may be due to the onset of the study in early stages of HIV infection. In addition, most haemophilic patients in this study were infected with HIV after their first years of life, compared with the prenatal or perinatal infection in vertical transmission of HIV. For this reason the patients in this study may be even more representative of the adult type of HIV infection, where the virus encounters an already developed immune system. It is possible that an evaluation period beyond 24 months could eventually lead to the observation of a benefit of IVIG treatment. However, any potential benefit must be balanced against the inconvenience and the time involved in the administration of the drug. ${ }^{22}$ The National Institutes of Health study clearly demonstrates the efficacy of IVIG in the reduction of bacterial infections and number of hospitalisations in prenatally or perinatally HIV infected children. But this effect was limited to the patients with more than $200 \mathrm{CD} 4+\mathrm{T}$ cells $/ \mu \mathrm{l}$, whereas in the patients already presenting with a CD4 $+\mathrm{T}$ cell count below $200 / \mu$ lat entry this benefit was not evident. ${ }^{11}$ In addition, another study conducted earlier but lacking a control group also reported a reduction in the number of infectious episodes. $^{23}$

The number of CD4+ $\mathrm{T}$ cells represents an important prognostic indicator ${ }^{5} 13$ and therefore is a useful laboratory tool to identify the immunodeficiency developing in HIV infection. In this study the absolute CD4 $+\mathrm{T}$ cell count and the ratio of $\mathrm{CD} 4+\mathrm{T}$ cells to lymphocytes were assessed at three month intervals. Both parameters declined in the two groups as shown in figs 1 and 2 . In addition both parameters showed a high standard error. This may be a reflection of our relatively small sample size. No statistically significant difference was detectable, so IVIG did not lead to a delay in the development of immunodeficiency when assessed by the CD4+ $\mathrm{T}$ cell count. In another study the number of patients whose CD4+ $T$ cell count improved during IVIG treatment was reported to be significantly higher than in the control group, but no details are available regarding the comparibility of the study groups and regarding the method of patient assignment to any of the study groups. ${ }^{10}$ The end points of the National Institutes of Health study did not include the CD4+ T cell count. ${ }^{11}$

This prospective, controlled study was conducted in order to evaluate the efficacy of IVIG in early stages of HIV infection in haemophilic patients. In conclusion, after 24 months no significant effect was detected in comparison with the control group as assessed by (1) the progression of HIV disease defined by the modified Brodt/Helm classification, (2) the number of infectious events and occurrence of HIV associated thrombocytopenia, and (3) the CD4+ T cell count. Whether there is a benefit of IVIG after manifestation of AIDS in haemophilic patients cannot be concluded from these data and needs further evaluation. This study was in part presented on the Seventh International
Conference on AIDS, Florence, 1991 .
The authors are grateful to Dr G Rosenkranz for help with the
statistical analysis and to Dr C Twist for carefully reading the manuscript. 
1 Johnson RE, Lawrence DN, Evatt BL, et al. Acquired immunodeficiency syndrome among patients attending hemophilia treatment centers and mortality experience of
hemophiliacs in the United States. Am J Epidemiol 1985; hemophiliacs

2 Teitel JM, Freedman JJ, Garvey MB, Kardish M. Two year evaluation of clinical and laboratory variables of immune function in 117 hemophiliacs seropositive or seronegative for HIV-1. Am f Hematol 1989;32:262-72.

3 Giesecke J, Scalia-Tomba G, Berntorp E, Schulman S, Stigendal L. Incidence of symptoms and AIDS in 146 Swedish haemophiliacs and blood transfusion recipients infected with human immunodeficiency virus. $B M \mathcal{F} 1988$; 297:99-102.

4 Goedert JJ, Kessler CM, Aledort LM, et al. A prospective study of human immunodeficiency virus type 1 infection and the development of AIDS in subjects with hemophilia. $N$ Engl $\mathcal{f}$ Med 1989;321:1141-8.

5 Wagner N, Bialek R, Radinger H, Becker M, Schneweis KE, Brackmann HH, Niese D. HIV-1 infection in a cohort of hrackmann HH, Niese D. HIV-1 infection in a cohort

6 Krasinski K, Borkowski W, Bonk S, Lawrence R, Chandwani S. Bacterial infections in human immunodeficiency virus-infected children. Pediatr Infect Dis $\mathcal{F}$ deficiency virus-i
$1988 ; 7: 323-8$.

7 Eibl MM, Wedgewood RJ. Intravenous immunoglobulin: a review. Immunodefic Rev 1989;1 (suppl): 1-42.

8 Buckley RH, Schiff RI. The use of intravenous immune globulin in immunodeficiency diseases. N Engl $\mathcal{J}$ Med 1991;325:110-7.

9 Eibl MM. Gamma globulin therapy. Current Opinion in Pediatrics 1990;2:935-40.

10 Calvelli TA, Rubinstein A. Intravenous gamma-globulin in infant acquired immunodeficiency syndrome. Pediatr Infect Dis 7 1986:5:207-10.

11 The National Institute of Child Health and Human Development Intravenous Immunoglobulin Study Group. Intravenous immune globulin for the prevention of bacterial infections in chidren with symptomatic human immunoinfections in chidren with symptomatic human immuno-
deficiency virus infection. $N$ Engl $\mathcal{f}$ Med 1991;325:73-80.
12 Brodt HR, Helm EB, Werner A, et al. Spontaneous course of LAV/HTLV III infection. Dtsch Med Wochenschr 1986;111: LAV/HT-80.

13 Jason JM, Stehr-Green J, Holman RC, Evatt BL. Human immunodeficiency virus infection in hemophilic children. Pediatrics 1988;82:565-70.

14 Bowker AH. A test for symmetry in contingency tables. Fournal of the American Statistical Association 1948;43: $572-4$

15 Pocock SJ, Geller NC. Interim analyses in randomized clinical trials. Drug Information fournal 1986;20:263-9.

16 Amman HJ, Ashman RF, Buckley RH, et al. Use of intravenous gamma globulin in antibody deficiency: results of a multicenter controlled trial. Clin Immunol Immunopathol 1982;22:60-7.

17 Ochs HD, Buckley RH, Pirofsky B, et al. Safety and patient acceptability of intravenous immune globulin in $10 \%$ maltose. Lancet 1980;ii:1158-9.

18 Schaad UB, Gianella-Borradori A, Perret B, Imbach P, Morell A. Intravenous immune globulin in symptomatic paediatric human immunodeficiency virus infection. Eur $\mathcal{f}$ Pediatr 1988;147:300-3.

19 Hunziker UA, Nadal D, Jendis JB, et al. Stable human immunodeficiency virus encephalopathy in two infants receiving early intravenous gammaglobulin plus antimicrobia

20 Kamani N, Lightman H, Leiderman J, Krilov RL. Pediatric acquired immunodeficiency syndrome-related complex: clinical and immunological features. Pediatr Infect Dis $\mathcal{f}$ 1988;7:383-8.

21 Bernstein LJ, Krieger BZ, Novick B, Sicklick MJ, Rubinstein A. Bacterial infections in the acquired immunodeficiency syndrome of children. Pediatr Infect Dis $\mathcal{F} 1985 ; 4: 472-5$.

22 Weeks JC, Tierney MR, Weinstein MC. Cost effectiveness of prophylactic intravenous immune globulin in chronic prophylactic intravenous immune globulin in chroc leukemia. $N$ Engl f Med 1991;325:81-6.

23 Hague RA, Yap PL, Mok JYQ, et al. Intravenous immunoglobulin in HIV infection: evidence for the efficacy of treatment. Arch Dis Child 1989;64:1146-50. 